- Prevalence and severity of caries in 4-5-year-old children in Amman was high; 67\% of the children had some caries experience and $33 \%$ had dmft greater than 4.

- Confectionary was reported to be regularly consumed by $76 \%$ of the $4-5$-year-old children and biscuits and/or cakes by $71 \%$. More than $50 \%$ were reported to drink canned fruit juice and carbonated drinks regularly between meals. Forty two percent were reported to consume teas with sugar.

- Consumption of confectionery had an independent effect on the prevalence of caries and consumption of teas with sugar had an independent effect on the severity of caries.

\title{
Food and drink consumption, sociodemographic factors and dental caries in 4-5-year-old children in Amman, Jordan
}

\author{
A. Sayegh, ${ }^{1}$ E. L. Dini, ${ }_{1}^{2}$ R. D. Holt ${ }^{3}$ and R. Bedi ${ }^{4}$
}

Objective To investigate the association between type of food and drink consumption, sociodemographic factors and prevalence and severity of caries in 4-5-year-old Jordanian children.

Method Two-stage random sampling procedure was used to select children enrolled in kindergartens in Amman. Clinical examinations were carried out by one examiner. Mothers completed a questionnaire relating to sociodemographic factors and food and drink consumption.

Results Snack foods were consumed by a high percentage of children. Amongst the most popular 'high in NME sugar snacks', confectionery was reported to be regularly consumed by $76 \%$ and biscuits and cakes by $71 \%$ of them. More than 50\% had carbonated drinks. Children from a lower social class, attending a kindergarten with lower tuition fees had more dessert, squashes and more teas with sugar. When all variables were considered, consumption of confectionery was independently associated with caries prevalence and consumption of teas with sugar was independently associated with caries severity.

Conclusion The types of foods and drinks consumed as snacks by young Jordanian children were similar to those of Western countries. In the absence of more widespread oral health promotion measures and in the presence of high prevalence and severity of caries, the oral health of Jordanian children is a matter of concern.

Sugars, and more particularly sucrose, are concluded to be the principal dietary cause of caries. ${ }^{1}$ Often contained in manufactured foods and drinks, sugars form a component of most human diets. In the UK, for example, sugars are believed to contribute 10$20 \%$ of food energy. ${ }^{2}$

It has been suggested that differences in diet and particularly sugar intake may be an important determinant of the variation in caries seen between social classes. ${ }^{3}$ However, the relationship between sugar consumption and caries is not always clear. Much of the evidence is circumstantial and has been open to criticism.

${ }^{1}$ Lecturer, University of Jordan; ${ }^{2}$ Lecturer, Eastman Dental Institute, University College London; $3^{*}$ Senior Lecturer, Eastman Dental Institute, University College London; ${ }^{4}$ Head of Unit, Transcultural Oral Health, Eastman Dental Institute, University College London ${ }^{*}$ Correspondence to: Dr R. D. Holt, Department of Transcultural Oral Health, Eastman Dental Institute, 256, Gray's Inn Road, London WC1X 8LD

Email:r.holt@eastman.ucl.ac.uk

\section{Refereed paper}

Received 23.07.01; Accepted 14.01.02

(๑) British Dental Journal 2002; 192: 37-42
Within the last two decades some reports have shown relatively clear associations between differing measures of sugar intake and occurence of caries $^{4-7}$ but others have shown differently. ${ }^{8,9}$ Some studies have also failed to demonstrate clear social class differences in consumption of sugar-containing foods. ${ }^{5,10}$

It has been suggested that the association between sugar consumption and caries is weak in countries where caries prevalence is low and that this failure may be partly a result of the introduction of preventive methods, particularly those involving fluoride. ${ }^{11-14}$ This will not be true in developing countries where preventive methods are less widely available and where sugar consumption may be higher and have a more detrimental effect. ${ }^{15,16}$ However, there is relatively little information about the amount of sugar consumed and patterns of consumption in developing countries. The information available suggests that sugar consumption is increasing and that it is higher in the Middle East than in other developing areas. ${ }^{16,17}$

Past failure to demonstrate a relationship between caries and sugar consumption may also have been related to inherent difficulties in measuring sugars intake and relating this to disease. Often, information about diet is drawn from questionnaires, completed on a single occasion and related to accumulated caries experience in the form of dmf/DMF values. Diet may change with time so this may not be an appropriate approach in older children and adults; it may be more suitable in young children where teeth have erupted more recently and where there has been less opportunity for dietary habits to have changed greatly.

The aims of this study were therefore:

1. To study the association between type of food/drink consumption and sociodemographic factors in preschool Jordanian children;

2. To study the association between prevalence and severity of caries and food/drink consumption in the same group of children.

\section{MATERIALS AND METHOD}

\section{Population and sampling}

The estimated population of Amman, capital city of Jordan, is $1,800,000$. The city is serviced with only low levels of fluoride water supply ( $0.3 \mathrm{ppm}$ on average). Fluoride toothpastes are thought to be widely available and use of fluoride supplements is low. At the time of the study, schools in Amman were independent 
and not state funded; therefore agreement for participation in the study was obtained separately for each school. A list of kindergartens in the city and the numbers of children attending these were obtained from the Department of Education. A total of 22,569 children were enlisted in the kindergartens at the time of the study. The 275 kindergartens on the list were then stratified by monthly tuition fee into seven categories: $<=10$ Jordanian Dinars (JDs); 1120JDs; 21-30JDs; 31-40JDs; 41-50JDs; 51-60JDs; >60JDs. The number of kindergartens $(\mathrm{K})$ and of children attending them $(\mathrm{N})$ in each category were: category $1(K=16 ; N=1,129)$, category 2 $(K=105 ; N=, 8806)$, category $3(K=49 ; N=4,516)$, category $4(K=49$; $\mathrm{N}=2,935)$, category $5(\mathrm{~K}=16 ; \mathrm{N}=1,806)$, category $6 \quad(\mathrm{~K}=16$; $\mathrm{N}=1,110)$, category $7(\mathrm{~K}=24 ; \mathrm{N}=2,267)$.

A two-stage sampling procedure was used within each strata. In the first stage a proportional simple random sampling procedure was used to select the kindergartens for the study. Using this method 34 kindergartens were selected. The number of kindergartens $(\mathrm{K})$ and of children attending the selected kindergartens $(\mathrm{N})$ by category were: category $1(K=2 ; N=137)$, category $2(K=13$; $\mathrm{N}=1,069)$, category $3(\mathrm{~K}=6 ; \mathrm{N}=534)$, category 4 ( $\mathrm{K}=6 ; \mathrm{N}=377)$, category $5(K=2 ; N=214)$, category $6(K=2 ; N=138)$, category $7(K=3$; $\mathrm{N}=279$ ). Head teachers were asked to consent to their kindergarten being a part of the survey. On refusal another kindergarten from the same stratum was randomly selected.

In the second stage and using class lists of children classified by age and gender from the sampled kindergartens, children were selected using a systematic random sampling procedure. Schools were asked to circulate a letter to parents of the selected children explaining the nature and purpose of the study, seeking consent to their child taking part and to collect the returns. Of the 1,200 children selected, forms were returned for a total of 1,140 children (95\%). Of the 60 who did not return their forms, 43 (72\%) were of children in schools in the highest tuition fee stratum.

\section{Questionnaires}

A questionnaire including questions on sociodemographic factors and food and drink consumption was sent to parents. The questionnaire, devised in the Arabic language, included questions about the types of snack foods and drinks consumed most often and the most usual foods eaten at the main meal times of breakfast and dinner. Questions offered checklists of suitable items as well as an open ended section for other types of food and drinks. The questionnaire was first tested in a pilot study in two kindergartens not included in the main study. Questions were modified before the main study.

In the final questionnaire the snack foods list included biscuits/cakes, confectionery (including candies, chocolates, lollipops, toffee), desserts (including ice-cream, fruit in syrup and jam sandwiches), savoury foods (cheese sandwiches, potato chips), chewing gum and fresh fruits. For drinks the list included fresh fruit juices, canned fruit juices, squashes, carbonated drinks, teas with sugar (tea with sugar and herb infusions with sugar). For breakfast, the list included milk with sugar, tea with sugar, savory items (thyme, olives, chickpeas/beans, eggs, sour cream and cheese) and marmalade/jam/honey/halawi. For dinner, the list included cooked vegetables with or without meat, milk with sugar, tea with sugar, savory (thyme, olives, sour cream, cheese, eggs, chickpeas/beans) and marmalade/jam/honey/halawi.

Snack foods and drinks were classified according to whether or not they were considered to contain non-milk extrinsic (NME) sugar (either added to taste or during manufacture). Amongst snack foods, biscuits/cakes, confectionery, desserts and chewing gum were classified as containing NME sugars. Savory snacks and fresh fruits were classified as not containing, or containing minimal amounts of NME sugars. Amongst drinks all those included were defined as containing NME sugars.
For foods eaten at breakfast or dinner, NME sugar containing items included milk/tea with sugar and marmalade/jam/honey/ halawi. Cooked vegetables (with or without meat) and savory foods were regarded as containing no, or minimal NME sugars.

Questionnaires were sent, together with the form seeking consent, to all selected children through the school. Parents were asked to return completed forms to the school head teacher. Illiterate mothers and/or fathers were helped to complete the questionnaires by their neighbours, older children or relatives.

\section{Clinical examination and diagnostic criteria}

Dental examinations were conducted in the schools by one examiner (A S) who was first trained and calibrated by an experienced epidemiologist ( $\mathrm{R}$ H). The calibration included 49 children in two kindergartens not selected for the main study. To check intraexaminer agreement duplicate examinations were also carried out for $10 \%$ of the sample. Kappa statistics for the presence or absence of caries were 0.86 for inter-examiner variability and 0.98 for intra-examiner variability. At the time of the examination, the investigator was unaware of the parent's responses to the questionnaire.

Children were examined at their kindergarten premises under natural light and not in direct sunlight. The child sat in an ordinary chair facing a window. A plane mirror and a periodontal probe were used. Diagnostic criteria depended on visual evidence of a lesion, with a blunt periodontal probe being used only to remove plaque.

Caries was recorded using the dmft index. A tooth was considered decayed (d) if there was visible evidence of cavitation (ie involving dentine), including untreated dental caries and filled teeth with recurrent caries. The missing component (m) included only those missing teeth believed to have been lost through caries. Conventions adopted for missing teeth were that in children under five years, any missing posterior tooth was considered as extracted due to caries, while a missing incisor tooth was considered as exfoliated unless no successor was obvious and definite caries was apparent in adjacent anterior teeth in which case it was regarded as lost due to caries. ${ }^{18}$

Examinations were carried out for the 1,140 children whose parents had given consent and had completed and returned questionnaires.

\section{Data analysis}

All data were processed and analysed at the Computer Centre, University of Jordan using SAS software and at the Eastman Dental Institute using SPSS. Chi-square was used to test the association between different types of food/drink consumption, and sociodemographic factors and caries prevalence.

Multiple logistic regression was then used to determine variables which had an independent effect on the prevalence of caries and on caries severity when others were taken into account. All sociodemographic variables and the dietary items that had shown a statistically significant association with caries prevalence and with caries severity in the univariate analysis were entered into the model. The multivariate analysis was carried out using a step-down analysis in which each variable was included in the initial model. Variables were dropped sequentially, with the variable showing the least evidence of statistically significant association dropped first and the analysis repeated until only those variables demonstrating statistically significant association at the 5\% level were included in the final model.

\section{RESULTS}

Results related to findings at dental examination and information from the completed questionnaires for the 1,140 children. This included 582 boys and 558 girls. Of the total, 569 were aged 4 years and 571 were 5 years old. 
Table 1 shows the number and proportions of children in relation to types of snack foods consumed and to sociodemographic factors. It also shows the prevalence of caries and the severity of caries in relation to snack food consumption. In this sample of children, savory snack foods and fresh fruit were reported to be the most popular snacks and chewing gum and desserts the least popular. Confectionery was said to be eaten regularly by $76 \%$ of the $4-5$-year-old children and biscuits/cakes by $71 \%$. It can be seen that more younger children (4-year-olds) and boys tended to consume confectionery and more girls had chewing gum.

In relation to the three socio-economic measures, there was a trend for more children from lower classes to have biscuits/cakes, confectionery, dessert foods and savory foods and fewer to have fresh fruit. Only in the case of dessert foods were social class differences statistically significant.

In relation to prevalence of caries, significantly more children with caries had confectionery and had dessert foods $(\mathrm{p}<0.05)$. When severity of caries was considered, significantly more children with dmft greater than 4 had dessert foods $(p<0.05)$.

Drinks consumed between mealtimes are shown in Table 2. Fewer children were reported as having drinks than snack food. Carbonated drinks were the most popular and fruit squashes the least. Fewer older children had canned fruit juices $(p<0.05)$. There was also some trend for more boys to have carbonated drinks and fruit squashes although the differences were not statistically significant.

More children from lower social classes drank teas with sugar and fruit squashes and fewer drank fresh fruit juices $(\mathrm{p}<0.05)$. More children from lower classes drank carbonated drinks but the difference was not statistically significant for all three social class measures. More children who had caries and more children who had dmft greater than 4 drank fruit squashes and teas with sugar $(\mathrm{p}<0.05)$.
Major types of foods consumed at breakfast are shown in Table 3. Both savory items and milk/tea with sugar were reported for more than $85 \%$ of the children with approximately one third having the food items that were high in NME sugars (marmalade/jam/honey/halawi). Breakfast food and drinks did not differ with age or gender and there was no consistent difference with all three social class measures. More of the children with caries were reported as having sweet food items at breakfast.

The findings in relation to foods and drinks taken at dinner were in some respect similar to those seen at breakfast. The great majority of children had savory foods at dinner time and about $40 \%$ had cooked vegetables with or without meat. Of the children, 50-60\% drank milk or tea with sugar at dinner time and just less than one third had items considered very high in NME sugars. There were no obvious differences with age but fewer girls had milk/tea with sugar and fewer had marmalade/jam/ honey/halawi at dinner time.

Consistently more children from lower social classes had cooked vegetables at dinner time $(\mathrm{p}<0.05)$. There were also trends for fewer children in lower classes to have milk/tea with sugar or to have savory items but these were not significant.

Although no social class differences were obvious in relation to children having items such as marmalade/jam/honey/halawi at dinner time, significantly more children with caries did so (30\%) compared with those who were caries free (23\%).

When dietary and socidemographic variables were combined in stepwise multiple logistic regression, six emerged as having a significant independent effect. Two dietary factors having an independent effect on caries prevalence were confectionery consumption between meals and having marmalade/jam/ honey/halawi at breakfast. In each case, the odds ratio suggested that children for whom these were reported had approxi-

\begin{tabular}{|c|c|c|c|c|c|c|c|}
\hline & \multirow[b]{2}{*}{$n$} & \multicolumn{6}{|c|}{ Snack foods } \\
\hline & & $\begin{array}{c}\text { Biscuits/cakes } \\
\mathrm{n}(\%)\end{array}$ & $\begin{array}{c}\text { Confectionery } \\
\mathrm{n}(\%)\end{array}$ & $\begin{array}{c}\text { Dessert } \\
\mathrm{n}(\%)\end{array}$ & $\begin{array}{c}\text { Savory } \\
\mathrm{n}(\%)\end{array}$ & $\begin{array}{c}\text { Chewing-gum } \\
\mathrm{n}(\%)\end{array}$ & $\begin{array}{c}\text { Fresh fruit } \\
\mathrm{n}(\%)\end{array}$ \\
\hline \multicolumn{8}{|l|}{ Age (years) } \\
\hline 4 & 569 & $409(71.9)$ & $450(79.1)$ & $322(56.6)$ & $465(81.7)$ & $336(59.1)$ & $443(77.9)$ \\
\hline 5 & 571 & $406(71.1)$ & $414(72.5)^{*}$ & $342(59.9)$ & $466(81.6)$ & $311(54.5)$ & 466 (81.6) \\
\hline \multicolumn{8}{|l|}{ Gender } \\
\hline Boys & 582 & $422(72.5)$ & $458(78.7)$ & $345(59.3)$ & $483(83.0)$ & $313(53.8)$ & $451(77.5)$ \\
\hline girls & 558 & $393(70.4)$ & $406(72.8)^{*}$ & $319(57.2)$ & $448(80.3)$ & $334(59.9)^{*}$ & $458(82.1)$ \\
\hline \multicolumn{8}{|l|}{ Kindergarten fees } \\
\hline$>40$ JDs & 235 & $162(68.9)$ & $170(72.3)$ & $114(48.5)$ & $178(75.7)$ & $134(57.0)$ & $193(82.1)$ \\
\hline 21-40 JDs & 384 & $276(71.9)$ & 304 (79.2) & $215(56.0)$ & $311(81.0)$ & $232(60.4)$ & $314(81.8)$ \\
\hline$<=10-20 \mathrm{JDs}$ & 521 & $377(72.4)$ & $390(74.9)$ & $335(64.3)^{*}$ & $442(84.8)^{*}$ & $281(53.9)$ & $402(77.2)$ \\
\hline \multicolumn{8}{|l|}{ Social class } \\
\hline III Manual - V/ not classified & 305 & $214(70.2)$ & $232(76.1)$ & $198(64.9)^{*}$ & $256(83.9)$ & $170(55.7)$ & $236(77.4)$ \\
\hline \multicolumn{8}{|l|}{ Mother's education } \\
\hline Interm. college/ University & 631 & $453(71.8)$ & 467 (74.0) & $352(55.8)$ & $508(80.5)$ & $347(55.0)$ & $518(82.1)$ \\
\hline Secondary school/ vocational training & 376 & $262(69.7)$ & $293(77.9)$ & $225(59.8)$ & $311(82.7)$ & $226(60.1)$ & $293(77.9)$ \\
\hline No schooling/Primary school/ not specified & 133 & $100(75.2)$ & $104(78.2)$ & $87(65.4)^{*}$ & $112(84.2)$ & $74(55.6)$ & $98(73.7)$ \\
\hline \multicolumn{8}{|l|}{ Cariesprevalence } \\
\hline Caries free & 375 & $261(69.6)$ & $261(69.6)$ & $197(52.5)$ & $311(82.9)$ & $200(53.3)$ & 305 (81.3) \\
\hline With caries & 765 & $554(72.4)$ & $603(78.8)^{*}$ & $467(61.0)^{*}$ & $620(81.0)$ & $447(58.4)$ & $604(79.0)$ \\
\hline \multicolumn{8}{|l|}{ Caries severity } \\
\hline $\mathrm{dmft}<=4$ & 766 & $543(70.9)$ & $568(74.2)$ & $422(55.1)$ & $630(82.2)$ & $427(55.7)$ & $603(78.7)$ \\
\hline $\mathrm{dmft}>4$ & 374 & $272(72.7)$ & $296(79.1)$ & $242(64.7)^{*}$ & $301(80.5)$ & $220(58.8)$ & $306(81.8)$ \\
\hline \multicolumn{8}{|c|}{ JDs - Jordanian dinars (1.00 British pounds sterling is equivalent to 1.014 Jordanian dinars) } \\
\hline${ }^{*} p<0.05$ & & & & & & & \\
\hline
\end{tabular}




\begin{tabular}{|c|c|c|c|c|c|c|}
\hline & \multicolumn{6}{|c|}{ Drinks } \\
\hline & $n$ & $\begin{array}{c}\text { Fresh fruit juices } \\
\mathrm{n}(\%)\end{array}$ & $\begin{array}{c}\text { Canned fruit juices } \\
\mathrm{n}(\%)\end{array}$ & $\begin{array}{l}\text { Squashes } \\
\mathrm{n}(\%)\end{array}$ & $\begin{array}{c}\text { Carbonated drinks } \\
\mathrm{n}(\%)\end{array}$ & $\begin{array}{c}\text { Teas with sugar } \\
\mathrm{n}(\%)\end{array}$ \\
\hline $\begin{array}{l}\text { Age (years) } \\
4 \\
5\end{array}$ & $\begin{array}{l}569 \\
571\end{array}$ & $\begin{array}{l}280(49.2) \\
290(50.8)\end{array}$ & $\begin{array}{l}326(57.3) \\
290(50.8)^{*}\end{array}$ & $\begin{array}{l}141(24.8) \\
160(28.0)\end{array}$ & $\begin{array}{l}325(57.1) \\
334(58.5)\end{array}$ & $\begin{array}{l}239(42.0) \\
240(42.0)\end{array}$ \\
\hline $\begin{array}{l}\text { Gender } \\
\text { Boys } \\
\text { girls }\end{array}$ & $\begin{array}{l}582 \\
558\end{array}$ & $\begin{array}{l}287(49.3) \\
283(50.7)\end{array}$ & $\begin{array}{l}306(52.6) \\
310(55.6)\end{array}$ & $\begin{array}{l}164(28.2) \\
137(24.6)\end{array}$ & $\begin{array}{l}353(60.7) \\
306(54.8)\end{array}$ & $\begin{array}{l}248(42.6) \\
231(41.4)\end{array}$ \\
\hline $\begin{array}{l}\text { Kindergarten fees } \\
>40 \text { JDs } \\
21-40 \text { JDs } \\
<=10-20 \text { JDs }\end{array}$ & $\begin{array}{l}235 \\
384 \\
521\end{array}$ & $\begin{array}{l}133(56.6) \\
205(53.4) \\
232(44.5)^{*}\end{array}$ & $\begin{array}{l}115(48.9) \\
226(58.9) \\
275(52.8)^{*}\end{array}$ & $\begin{array}{c}49(20.9) \\
92(24.0) \\
160(30.7)^{*}\end{array}$ & $\begin{array}{l}113(48.1) \\
233(60.7) \\
313(60.1)^{*}\end{array}$ & $\begin{array}{l}45(19.1) \\
143(37.2) \\
291(55.9)^{*}\end{array}$ \\
\hline $\begin{array}{l}\text { Social class } \\
\text { I-III Non manual } \\
\text { III Manual-V/ not classified }\end{array}$ & $\begin{array}{l}835 \\
305\end{array}$ & $\begin{array}{l}436(52.2) \\
134(43.9)^{*}\end{array}$ & $\begin{array}{l}474(56.8) \\
142(46.6)^{*}\end{array}$ & $\begin{array}{l}203(24.3) \\
98(32.1)^{*}\end{array}$ & $\begin{array}{l}479(57.4) \\
180(59.0)\end{array}$ & $\begin{array}{l}305(36.5) \\
174(57.0)^{*}\end{array}$ \\
\hline $\begin{array}{l}\text { Mother's education } \\
\text { Interm. college/ University } \\
\text { Secondary school/ vocational training } \\
\text { No schooling/ Primary school/ not specified }\end{array}$ & $\begin{array}{l}631 \\
376 \\
133\end{array}$ & $\begin{array}{l}340(53.9) \\
174(46.3) \\
56(42.1)^{*}\end{array}$ & $\begin{array}{l}350(55.5) \\
213(56.6) \\
53(39.8)^{*}\end{array}$ & $\begin{array}{l}142(22.5) \\
111(29.5) \\
48(36.1)^{*}\end{array}$ & $\begin{array}{l}341(54.0) \\
231(61.4) \\
87(65.4)^{*}\end{array}$ & $\begin{array}{l}219(34.7) \\
171(45.5) \\
89(66.9)^{*}\end{array}$ \\
\hline $\begin{array}{l}\text { Caries prevalence } \\
\text { Caries free } \\
\text { With caries }\end{array}$ & $\begin{array}{l}375 \\
765\end{array}$ & $\begin{array}{l}203(54.1) \\
367(48.0)\end{array}$ & $\begin{array}{l}189(50.4) \\
427(55.8)\end{array}$ & $\begin{array}{c}78(20.8) \\
223(29.2)^{*}\end{array}$ & $\begin{array}{l}202(53.9) \\
457(59.7)\end{array}$ & $\begin{array}{c}130(34.7) \\
349(45.6)^{*}\end{array}$ \\
\hline $\begin{array}{l}\text { Caries severity } \\
\mathrm{dmft}<=4 \\
\mathrm{dmft}>4\end{array}$ & $\begin{array}{l}766 \\
374\end{array}$ & $\begin{array}{l}391(51.0) \\
179(47.9)\end{array}$ & $\begin{array}{l}402(52.5) \\
214(57.2)\end{array}$ & $\begin{array}{l}181(23.6) \\
120(32.1)^{*}\end{array}$ & $\begin{array}{l}435(56.8) \\
224(59.9)\end{array}$ & $\begin{array}{l}291(38.0) \\
188(50.3)^{*}\end{array}$ \\
\hline
\end{tabular}

mately 1.5 times the risk of having caries. Only one dietary factor, consumption of teas with sugar, had an independent effect on the severity of caries. Age and kindergarten tuition fees showed significance with both caries prevalence and severity.

\section{DISCUSSION}

A review of the literature on the consumption of sugar in developing countries has emphasised that sugar (sucrose) use is increasing, particularly in Middle Eastern countries where con-

\begin{tabular}{|c|c|c|c|c|}
\hline & \multicolumn{4}{|c|}{ Food and drinks at breakfast } \\
\hline & $\mathrm{n}$ & $\begin{array}{c}\text { Milk/Tea with sugar } \\
\mathrm{n}(\%)\end{array}$ & $\begin{array}{c}\text { Savory } \\
\mathrm{n}(\%)\end{array}$ & $\begin{array}{c}\text { Marmalade/Jam/Honey/Halawi } \\
\mathrm{n}(\%)\end{array}$ \\
\hline $\begin{array}{l}\text { Age (years) } \\
4 \\
5\end{array}$ & $\begin{array}{l}569 \\
571\end{array}$ & $\begin{array}{l}486(85.4) \\
495(86.7)\end{array}$ & $\begin{array}{l}508(89.3) \\
514(90.0)\end{array}$ & $\begin{array}{l}180(31.6) \\
207(36.3)\end{array}$ \\
\hline $\begin{array}{l}\text { Gender } \\
\text { Boys } \\
\text { girls }\end{array}$ & $\begin{array}{l}582 \\
558\end{array}$ & $\begin{array}{l}505(86.8) \\
476(85.3)\end{array}$ & $\begin{array}{l}525(90.2) \\
497(89.1)\end{array}$ & $\begin{array}{l}209(35.9) \\
178(31.9)\end{array}$ \\
\hline $\begin{array}{l}\text { Kindergarten fees } \\
>40 \text { JDs } \\
21-40 \text { JDs } \\
<=10-20 \text { JDs }\end{array}$ & $\begin{array}{l}235 \\
384 \\
521\end{array}$ & $\begin{array}{l}199(84.7) \\
314(81.8) \\
468(89.8)^{*}\end{array}$ & $\begin{array}{l}201(85.5) \\
341(88.8) \\
480(92.1)^{*}\end{array}$ & $\begin{array}{l}56(23.8) \\
136(35.4) \\
195(37.4)\end{array}$ \\
\hline $\begin{array}{l}\text { *Social class } \\
\text { I-III Non manual } \\
\text { III Manual-V/not classified }\end{array}$ & $\begin{array}{l}835 \\
305\end{array}$ & $\begin{array}{l}717(85.9) \\
264(86.6)\end{array}$ & $\begin{array}{l}752(90.1) \\
270(88.5)\end{array}$ & $\begin{array}{c}289(34.6) \\
98(32.1)\end{array}$ \\
\hline $\begin{array}{l}\text { Mother's education } \\
\text { Interm. college/ University } \\
\text { Secondary school/ vocational training } \\
\text { No schooling/ Primary school/ not specified }\end{array}$ & $\begin{array}{l}631 \\
376 \\
133\end{array}$ & $\begin{array}{l}540(85.6) \\
323(85.9) \\
118(88.7)\end{array}$ & $\begin{array}{l}565(89.5) \\
334(88.8) \\
123(92.5)\end{array}$ & $\begin{array}{l}214(33.9) \\
131(34.8) \\
42(31.6)\end{array}$ \\
\hline $\begin{array}{l}\text { Caries prevalence } \\
\text { Caries free } \\
\text { With caries }\end{array}$ & $\begin{array}{l}375 \\
765\end{array}$ & $\begin{array}{l}325(86.7) \\
656(85.8)\end{array}$ & $\begin{array}{l}335(89.3) \\
687(89.8)\end{array}$ & $\begin{array}{c}101(26.9) \\
286(37.4)^{*}\end{array}$ \\
\hline $\begin{array}{l}\text { Caries severity } \\
\mathrm{dmft}<=4 \\
\mathrm{dmft}>4\end{array}$ & $\begin{array}{l}766 \\
374\end{array}$ & $\begin{array}{l}649(84.7) \\
332(88.8)\end{array}$ & $\begin{array}{l}681(88.9) \\
341(91.2)\end{array}$ & $\begin{array}{l}247(32.2) \\
140(37.4)\end{array}$ \\
\hline $\begin{array}{l}\text { JDs - Jordanian dinars } \\
{ }^{*} p<0.05\end{array}$ & & & & \\
\hline
\end{tabular}


sumption seems to be higher than in other developing areas. ${ }^{16}$ Studies of food habits, ${ }^{17}$ nutritive value of the diet ${ }^{19}$ or types of food consumption and dental caries prevalence ${ }^{20,21}$ have been carried out in Arabian countries but to our knowledge there is no previous information about the most popular choice of items for snacks or drinks between meals amongst young children in Jordan.

Jordan represents a country with extensive links with Western countries, especially the USA and the UK but which has retained a strong Arabic identity. This study has considered the type of food/drink consumption and sociodemographic factors amongst preschool children from the capital city of Amman, Jordan. It has also considered the association between food/drink consumption and prevalence and severity of caries in the same children.

Snack foods were consumed by a high percentage of children. Savory foods and fresh fruit were reported to be the most popular snacks amongst them. Savory foods were reported to be eaten by $82 \%$ of the children and fresh fruit by $80 \%$ of them, perhaps reflecting the high accessibility of these foods. Amongst the most popular 'high in NME sugar snacks', confectionery was reported to be consumed by $76 \%$ of the $4-5$-year-old children and biscuits and/or cakes by $71 \%$ of them.

One study carried out of 4-6-year-olds in Saudi Arabia also reported a high percentage (88.2\%) of children to regularly have sweet snacks. ${ }^{20}$ Amongst 4-year-old children in Norwich, England, biscuits/cakes were also a popular food item but these were eaten by only $40 \%$ of the children and confectionery by only $4 \%$ of them (as mid-morning or at school breaktime snacks). ${ }^{5}$

It may be concluded that savory snacks are a very popular food choice amongst both Jordanian and English children although there may be some differences in the pattern of consumption of these items. In the most recent National Diet and Nutrition Survey of young people in England 22 92\% of 4-6-year- old boys and $91 \%$ of girls of the same age were reported to consume savory snacks, a little higher than those observed in boys and girls in Jordan.

More than 50\% of children in the current study were reported to regularly consume canned fruit juices and carbonated drinks. Squashes were reported to be consumed regularly as snack drinks by $26 \%$ and teas with sugar by $42 \%$ of the Jordanian children investigated. A higher percentage of English children in Norwich (47\%) were reported to consume fruit squash at mid-afternoon or at school. ${ }^{5}$ Higher percentages of children of similar age (75\%) were reported to have canned soft drinks and packed fruit juices in the capital of Saudi Arabia ${ }^{20}$ and to have carbonated drinks (67\%) in England ${ }^{22}$ reflecting the increasing popularity of this type of drink.

The study has shown consistently that children who were attending kindergartens with the lowest monthly fees, who were from families in social classes III Manual-V (or who could not be classified) and whose mother had less education, had more dessert, more squashes, more teas with sugar and less fresh fruits and fresh fruit juices than did less disadvantaged children. The study has also shown that a child's consumption of dessert, squashes and teas with sugar was associated with both caries prevalence and severity. The study in Norwich gave little evidence of the influence of social class on the consumption of snacks or drinks as a whole or to consumption of sweet items amongst English children of the same age, but differences in caries prevalence were seen between social classes. ${ }^{5}$ However in a larger British study, similarly to the Jordanian children, 4-6-year-olds from less advantaged households in England were less likely to drink fruit juice or to have eaten fruit. ${ }^{22}$ Caries prevalence in young children from Scandinavian countries has also been found to be independently associated both with the mother's (young) age and daily sugar consumption in candies and in beverages. ${ }^{23,24}$

\begin{tabular}{|c|c|c|c|c|c|}
\hline & \multirow[b]{2}{*}{$n$} & \multicolumn{4}{|c|}{ Food and drinks at dinner } \\
\hline & & $\begin{array}{l}\text { Cooked vegetables with/without meat } \\
\qquad \mathrm{n}(\%)\end{array}$ & $\begin{array}{l}\text { Milk/Tea with sugar } \\
\mathrm{n}(\%)\end{array}$ & $\begin{array}{l}\text { Savory } \\
\mathrm{n}(\%)\end{array}$ & $\begin{array}{c}\text { Marmalade/ Jam/ Honey/ Halawi } \\
\mathrm{n}(\%)\end{array}$ \\
\hline \multicolumn{6}{|l|}{ Age (years) } \\
\hline 4 & 569 & $237(41.7)$ & $328(57.6)$ & 509 (89.5) & $155(27.2)$ \\
\hline 5 & 571 & $233(40.8)$ & $330(57.8)$ & $509(89.1)$ & $163(28.5)$ \\
\hline \multicolumn{6}{|l|}{ Gender } \\
\hline Boys & 582 & 229 (39.3) & $357(61.3)$ & $526(90.4)$ & $183(31.4)$ \\
\hline girls & 558 & $241(43.2)$ & $301(53.9)^{*}$ & $492(88.2)$ & $135(24.2)^{*}$ \\
\hline \multicolumn{6}{|l|}{ Kindergarten fees } \\
\hline$>40 \mathrm{JDs}$ & 235 & $73(31.1)$ & $172(73.2)$ & $218(92.8)$ & $49(20.9)$ \\
\hline $21-40$ JDs & 384 & $131(34.1)$ & $213(55.5)$ & $338(88.0)$ & $113(29.4)$ \\
\hline$<10-20$ JDs & 521 & $266(51.1)^{*}$ & $273(52.4)^{*}$ & $462(88.7)$ & $156(29.9)^{*}$ \\
\hline \multicolumn{6}{|l|}{ Social class } \\
\hline I-III Non manual & 835 & 308 (36.9) & $500(59.9)$ & 756 (90.5) & $236(28.3)$ \\
\hline III Manual-V/not classified & 305 & $162(53.1)^{*}$ & $158(51.8)^{*}$ & $262(85.9)^{*}$ & $82(26.9)$ \\
\hline \multicolumn{6}{|l|}{ Mother's education } \\
\hline Interm. college/ University & 631 & 241 (38.2) & $367(58.2)$ & 561 (88.9) & $176(27.9)$ \\
\hline Secondary school/ vocational training & 376 & $144(38.3)$ & $216(57.4)$ & $345(91.8)$ & $105(27.9)$ \\
\hline No schooling/Primary school/ not specified & 133 & $85(63.9)^{*}$ & $75(56.4)$ & $112(84.2)$ & $37(27.8)$ \\
\hline \multicolumn{6}{|l|}{ Caries prevalence } \\
\hline Caries free & 375 & $140(37.3)$ & $204(54.4)$ & 335 (89.3) & $88(23.5)$ \\
\hline With caries & 765 & $330(43.1)$ & $454(59.3)$ & $683(89.3)$ & $230(30.1)^{*}$ \\
\hline \multicolumn{6}{|l|}{ Cariesseverity } \\
\hline $\mathrm{dmft}<=4$ & 766 & $307(40.1)$ & $429(56.0)$ & $693(90.5)$ & $208(27.2)$ \\
\hline $\mathrm{dmft}>4$ & 374 & $163(43.6)$ & $229(61.2)$ & $325(86.9)$ & $110(29.4)$ \\
\hline \multicolumn{6}{|l|}{ JDs - Jordanian dinars } \\
\hline
\end{tabular}




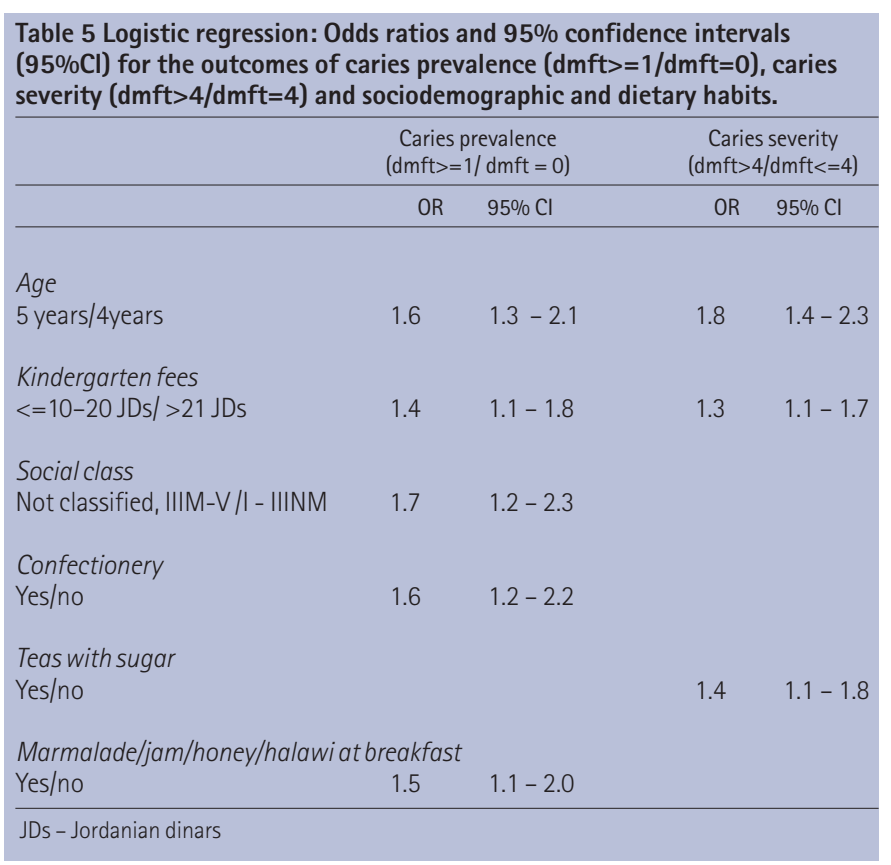

Food choices at breakfast and at dinnertime by Jordanian children have not been studied before and neither has the influence of social class on these choices. There were no consistent differences between the items eaten at breakfast and at dinner time in relation to any of the three social class measures but significantly more children with caries were reported to consume marmalade/ jam/ honey/ halawi at breakfast and dinner. When all the variables were considered, consumption of confectionery and having marmalade/ jam/honey/halawi at breakfast were independently associated with the prevalence of caries. Consumption of teas with sugar had an independent effect on severity of caries. Age and kindergarten tuition fees showed significance with both caries prevalence and severity.

A global change in the structure of diet has occurred in recent decades with an increase in the consumption of fatty and sugary foods. ${ }^{25,26}$ Data from surveys carried out in Arabian countries have also shown a change in dietary patterns of mothers and children, with a trend following that seen elsewhere towards the consumption of foods rich in fat, cholesterol and refined salt and sugar. ${ }^{17}$ Results of the present study suggest that the global change in dietary patterns and the availability of a common food world market may have affected the choice of items given to young children in Jordan, particularly the choices of snack foods and drinks high in NME sugars. The consumption of these types of foods and drinks as snacks was similar to that of Western countries.
In the presence of a high prevalence of caries (only 33\% of the children were caries free) and high caries severity (33\% of the children had dmft greater than 4) and in the absence of more widespread oral health promotion measures, the oral health of Jordanian children is a matter of concern.

1. Rugg-Gunn A J. Diet and dental caries. In Murray J J. Prevention of oral disease. pp 3 31. Oxford: Oxford University Press, 1996.

2. Department of Health. Committee on Medical Aspects of Food Policy. Dietary sugars and human disease. Report on Health and Social Subjects, $n$ 37. London: HMSO, 1989.

3. Rugg-Gunn A J. Nutrition and dental health. pp 338-359. Oxford: Oxford University Press, 1993.

4. Holbrook W P, Kristinsson M J, Gunnarsdottir S, Briem B. Caries prevalence, Streptococcus mutans and sugar intake among 4-year-old urban children in Iceland. Community Dent Oral Epidemiol 1989; 17: 292-295.

5. Holt R D. Foods and drinks at four daily time intervals in a group of young children BrDent J 1991: 171: 137-143.

6. Stecksen-Blicks $C_{1}$ Holm A-K. Between meal eating, toothbrushing frequency and dental caries in 4-year-old children in the north of Sweden. Int J Paediatr Dent 1995; 5: 67-72.

7. Kalsbeek $H$, Verrips $G H$. Consumption of sweet snacks and caries experience of primary school children. Caries Res 1994; 28: 477-483.

8. Burt B A, Szpunar S M. The Michigan study: the relationship between sugars intake and dental caries over three years. Int Dent J 1994; 44: 230-240.

9. Szpunar S M, Eklund SA, Burt B A. Sugar consumption and caries risk in schoolchildren with low caries experience. Community Dent Oral Epidemiol 1995; 23: 142-146.

10. Walker A, Gregory J, Bradnock G, Nunn J, White D. National diet and nutrition survey: young people aged 4 to 18 years. Vol 2: Report of the oral health survey. London: The Stationery Office, 2000

11. Marthaler T M. Changes in the prevalence of dental caries: how much can be attributed to changes in diet? Caries Res 1990; 24 (Suppl 1): 3-15.

12. Konig K G, Navia J M. Nutritional role of sugars in oral health. Am J Clin Nutr 1995; 62: $275 S-282 S$.

13. Ruxton C H, Garceau FJ, Cottrell R C. Guidelines for sugar consumption in Europe: is a quantitative approach justified? Eur J Clin Nutr 1999; 53: 503-513.

14. Gibson S, Williams S. Dental caries in pre-school children: associations with socia class, toothbrushing habit and consumption of sugars and sugar-containing foods. Further analysis of data from the National Diet and Nutrition Survey of children aged 1.5-4.5 years. Caries Res 1999; 33: 101-113.

15. Woodward M, Walker A R P. Sugar consumption and dental caries: evidence from 90 countries. BrDent J 1994; 23: 297-302.

16. Ismail A I, Tanzer J M, Dingle J L. Current trends of sugar consumption in developing societies. Community Dent Oral Epidemiol 1997; 25: 438-443.

17. Musaiger A 0 . Food habits of mothers and children in two regions of Oman. Nutr Health 1996; 11:29-48.

18. Palmer J D, Anderson R J, Downer M C. Guidelines for prevalence studies of dental caries. Community Dent Health 1984; 1: 55-66.

19. Musaiger A O, Ahmed M A, Rao M V. Nutritive value of traditional sweets consumed in the Arab Gulf countries. Int J Food Sci Nutr 2000; 51: 403-408.

20. Wyne A H, Khan N. Use of sweet snacks, soft drinks and fruit juices, tooth brushing and first dental visit in high DMFT 4-6-year-olds of Riyadh region. Indian J Dent Res 1995; $6: 21-24$.

21. Al-Shammery A R. Caries experience of urban and rural children in Saudi Arabia. J Public Health Dent 1999; 59: 60-64.

22. Gregory J, Lowe S. National diet and nutrition survey: young people aged 4 to 18 years. Vol 1: Report of the diet and nutrition survey. London: The Stationery Office, 2000.

23. Grindefjord M, Dahllof G, Nilsson B, Modeer T. Stepwise prediction of dental caries in children up to 3.5 years of age. Caries Res $1996 ; 30: 245-266$.

24. Mattila M L, Rautava P, Sillanpaa M, Paunio P. Caries in five-year-old children and associations with family-related factors. J Dent Res 2000; 79: 875-881.

25. Holmboe-Ottesen G. Global trends in food consumption and nutrition. Tidsskr Nor Laegeforen 2000; 120: 78-82.

26. Popkin B M. The nutrition transition and obesity in the developing world. J Nutr 2001; 131: $8715-8735$ 